\title{
RELIABILITY AND USEFULNESS OF HALF-SQUAT 1RM ESTIMATION THROUGH MOVEMENT VELOCITY IN U18 SOCCER PLAYERS
}

\author{
Pedro Moreno-Navarro; José Luis Hernández-Davó; \\ Iván Peña-González
}

Department of Sport Sciences of Miguel Hernandez University, Spain.

\section{ABSTRACT}

Introduction: Assessment of strength in youth athletes using a safety, time-efficient and reliable test is crucial for strength and conditioning professionals. The purpose of this study was to examine the reliability of the one-repetition maximum (1RM) estimation through movement velocity in youth soccer players. In addition, the relationships between 1RM estimation with peak power (PP), jumping and sprinting performance w ere checked. Material and methods: Twenty -two youth soccer players (16.8 \pm 0.6 years) took part in the study. Participants completed a $1 \mathrm{RM}$ estimation in the half-squat, squat jump (SJ), countermovement jump (CMJ) and $30 \mathrm{~m}$ sprint in three different occasions. Results: The 1 RM estimation showed good absolute $(\mathrm{SEM}<10 \%)$ and relative (ICC $>0.7)$ reliability scores. The estimated $1 \mathrm{RM}$ value was significantly low er in the trial 1 compared to the trials 2 and 3 . The estimated $1 \mathrm{RM}$ and the PP output showed significant correlations $(\mathrm{r}=0.538$ 0.560) with jumping and sprinting performance. Discussion: These data suggest the necessity to perform at least one familiarization session to obtain a reliable 1RM estimation through movement velocity in youth soccer players. Once youth soccer players are familiarized with the 1RM estimation protocol, coaches could use this evaluation to obtain a reliable measure of players' maximal strength in a time-efficient way.

Keywords: strength, evaluation, youth, soccer

\section{FIABILIDAD Y UTILIDAD DE LA ESTIMACIÓN DEL 1RM EN MEDIA SENTADILLA A TRAVÉS DE LA VELOCIDAD DE MOVIMIENTO EN JUGADORES DE FÚTBOL SUB18}

\begin{abstract}
RESUMEN
Introducción: La evaluación de la fuerza en los deportistas mediante el uso de un test seguro, eficiente y fiable es crucial para los profesionales del acondicionamiento físico. El objetivo de este estudio fue examinar la fiabilidad de la estimación de la repetición máxima (1RM) a través de la velocidad de movimiento en jóvenes jugadores de fútbol. Además, se analizó las relaciones entre la estimación de $1 \mathrm{RM}$ con el pico de potencia (PP), la altura de salto y el sprint. Material y métodos: Veintidós jóvenes jugadores de fútbol (16,8 \pm 0,6 años) participaron en el estudio. Los participantes completaron un test de $1 \mathrm{RM}$ en media sentadilla, squat jump (SJ), salto en contra movimiento (CMJ) y sprint de $30 \mathrm{~m}$ en tres ocasiones diferentes. Resultados: La estimación del 1RM mostró buenos valores de fiabilidad absoluta (SEM $<10 \%$ ) y relativa (ICC $>0.7)$. El valor estimado de $1 \mathrm{RM}$ fue significativamente menor en la prueba 1 en c comparación con las pruebas 2 y 3 . La estimación del 1RM y PP mostraron correlaciones significativas ( $r=0.538-0.560)$ con el rendimiento en saltos y sprint. Discusión: Estos datos sugieren la necesidad de realizar al menos una sesión de familiarización para obtener una estimación fiable d el $1 \mathrm{RM}$ a través de la velocidad de movimiento en jugadores de fútbol juveniles. Una vez que los jugadores de fútbol juveniles estén familiarizados con el protocolo de estimación $1 \mathrm{RM}$, los entrenadores podrían usar esta evaluación para obtener una medida fiable de la fuerza máxima de los jugadores de una manera eficiente en el tiempo.
\end{abstract}

Palabras clave: fuerza, evaluación, juventud, fútbol

Correspondence:

Iván Peña-González

ipena@umh.es

Department of Sport Sciences of Miguel Hernandez University, Spain.

Submitted: $17 / 03 / 2020$

Accepted: $21 / 04 / 2020$ 
INT RODUCTION

Soccer performance is determined by multiple variables, including technical, tactical, physical and psychological factors (Aguiar, Botelho, Lago, Maças \& Sampaio, 2012). Although during a match the aerobic system predominates (Stone \& Kilding, 2009), short and intermittent high-intensity actions are crucial for soccer success, despite representing a small proportion of the overall match (Carling, Le Gall \& Dupont, 2012; Stolen, Chamari, Cas tagna \& Wisloff, 2005). For example, straight sprint actions are the most frequent events in goal situations (Faude, Koch \& Meyer, 2012). In this regard, the athl etes' strength levels have been suggested as a key factor for sprinting and jumping performance (Comfort, Stewart, Bloom \& Clarkson, 2014; Weakley et al., 2017). For example, several authors have shown strong correlations between variables such as one repetition maximum (1RM) and sprinting time (Comfort et al., 2014) and jum ping performance (Weakley et al., 2017). For that reason, the inclusion of strength training sessions within the habitual training schedule has become essential in soccer (Asadi, Ramírez-Cam pillo, Arazi \& Saez de Villareal, 2018; Rodríguez-Rosell et al., 2016). Consequently, for a proper resistance training prescription, some authors have highlighted the importance of assessing the strength levels in soccer players (Faude et al., 2012).

Among the different ways to analyze maximal strength, the $1 \mathrm{RM}$ is one of the most used tests for evaluating muscular strength (Kraemer et al., 2002). The 1RM test is considered the gold standard for maximal strength evaluation (Seo et al., 2012) and offers the possibility of establishing initial loads and loadprogressions in strength training programs (Ryman-Augustsson \& Svantesson, 2013). Due to the extensive use of the $1 \mathrm{RM}$ test, it is crucial that the test shows high-reliability scores. Thus, strong research has looked into the reliability of the 1RM test using different population such as untrained middle-aged individuals (Levinger, Goodman, Hare, Jerums, Toia \& Selig, 2009; McCurdy, Langford, Cline, Doscher \& Hoff, 2004; Seo et al., 2012; Tagesson \& Kvist, 2007) and well-trained individuals (Comfort et al., 2014; Weakley et al., 2017). In this regard, the 1RM test has shown high to very-high reliability scores (e.g. intraclass correlation coefficient [ICC] > 0.91) (Seo et al., 2012), although several authors have reported differences in the test-retest 1RM squat values (Ritti-Dias, Avelar, Salvador \& Cyrino, 2011; Ryman-Augustsson \& Svantesson, 2013). Therefore, it is a source of debate whether the 1RM test has a learning effect, and, in consequence, if it needs a familiarization process, especially in young individuals with no experience in resistance training (Ritti-Dias et al., 2011). In addition, is still controversial if the $1 \mathrm{RM}$ test requirements (high muscular, tendon and bone stress) are unsafe (Rontu, Hannula, Leskinen, Linnamo \& Salmi, 2010) or not (Faigenbaum, Milliken \& Westcott, 2003) for young populations. 
Due to the afferomentioned dificulties in applying direct $1 \mathrm{RM}$ evaluations, the use of barbell velocity (velocity-based resistance training) using linear position transducer has emerged as a more practical alternative (Conceiçao, Fernandes, Lewis, González-Badillo \& Jiménez-Reyes, 2016; Loturco et al., 2016; Loturco et al., 2017). This method is based on the linear load-velocity relationship and allows coaches, not only to determine power output across different intensities but also to estimate 1RM with very high accuracy (González-Badillo \& Marques, 2010). In addition, the load-velocity relationship has proved to be very strong in a wide range of exercises and different populations (Balsalobre-Fernández, Marchante, Baz-Valle, Alonso-Molero, Jiménez \& Muñoz-López, 2017; González-Badillo \& Marques, 2010; Loturco et al., 2017). Some of the advantages of this kind of evaluation are reductions in injury risk and decreases in the time spent during evaluation (Conceiçaco et al., 2016; Jidovtseff, Harris, Crielaard \& Cronin, 2011; Loturco et al., 2016). The validity and reliability of strength evaluation using movement velocity have been previously established in trained and highly-trained individuals (González-Badillo \& Marques, 2010; González-Badillo \& Sánchez-Medina, 2010), with ICC values over 0.9 (Balsalobre-Fernández et al., 2017; Marques \& Izquierdo, 2014). Nevertheless, to the best of the authors' knowledge, there is no research concerning the reliability of the $1 \mathrm{RM}$ estimation using movement velocity with a submaximal load in young soccer players.

Thus, the aim of the present study was to analyse the reliability and the learning effect in the 1RM estimation through movement velocity in young soccer players. A secondary aim of this study was to evaluate the relationships the estimated $1 \mathrm{RM}$ value with variables linked to soccer success such as jumping and sprinting performance.

\section{Method}

Design

A within participants test-retest study design was used to assess the reliability of the $1 \mathrm{RM}$ estimation in the half-squat exercise using movement velocity. Participants attended three testing sessions separated by 1 week. During all the sessions, the estimation of $1 \mathrm{RM}$ in the half-squat exercise using movement velocity was evaluated. Additionally, within the same testing sessions, squat jump (SJ), countermovement jump (CMJ) and 30-meter linear sprint (30-m sprint) performance was also evaluated to assess the relationships between these variables and the estimated 1RM value. Aiming at avoiding experimental variability, all subjects were scheduled at the same time for each testing session. Before testing, all subjects completed a standardized warm-up consisting of 5 minutes of self-selected light-to-moderate runs, lower- 
limb dynamic stretching and sub-maximal attempts of sprinting and jumping tests.

\section{Participants}

A total of 22 young male soccer players (age: $16.8 \pm 0.6$ y ears; height: 174.1 $\pm 5.6 \mathrm{~cm}$; weight: $65.3 \pm 7.5 \mathrm{~kg}$ ) took part in the study. All the subjects were licensed and reported, at least, a minimum of eight years' experi ence in soccer training and competition. Nevertheless, subjects had no experience in regular resistance training and strength evaluation. The subjects and their guardians were fully informed about the research and written informed consent was signed prior to participation in the study. An Ethics Committee from the Miguel Hernandez University approved this study and it conformed to the recommendations of the Declaration of Helsinki.

\section{Testing}

One repetition maximum (1RM) in the half-squat exercise. The $1 \mathrm{RM}$ estimation for the players was carried out in a Smith Machine (Multipower M953; Technogym, Gambettola, Italy), and the kinematic data were recorded using a linear position transducer (T-Force system, Ergotech, Spain), which recorded the bar position with an analog-to-digital conversion rate of $1,000 \mathrm{~Hz}$ and an accuracy of $0.0002 \mathrm{~m}$. The linear transducer was interfaced to a computer by means of a 14-bit analog-to-digital data acquisition board, in which specialized software application (T-Force Dynamic Measurement System, T-Force system, Ergotech, Spain) automatically calculated the relevant kinetic and kinematic parameters. A high validity and reliability of this system has been previously reported (González-Badillo \& Marques, 2010).

For the 1RM estimation half-squat test, subjects started from a shoulderwidth stance apart and the barbell resting on the upper-back, approximately at the level of the acromion, with the knees and hips fully extended. Each subject descended until his knees reached $90^{\circ}$ (thighs parallel to the ground), and subsequently, ascended to the upright position (Ryman-Augustsson \& Svantesson, 2013). Subjects started with an absolute load representing the $50 \%$ of their body mass and thereafter, the load was gradually increased in $10-\mathrm{kg}$ until the mean propulsive velocity was $<0.5 \mathrm{~m} \cdot \mathrm{s}^{-1}$. Using this submaximal load, participants performed 4 intended maximal repetitions and the 1RM was automatically estimated by the specialized software of the linear position transducer. Several studies have supported the use of movem ent velocity for 1RM estimation (González-Badillo \& Sánchez-Medina, 2010; Izquierdo et al., 2006; Loturco et al., 2016). To avoid cumulated fatigue, the rest interval between sets was set at 4 minutes. 
Jumping tests. The jumping ability was tested using the SJ and the CMJ. For each jumping modality, subjects performed two maximal attempts on a contact platform (Globus Ergotester $®$, Italia) according to Bosco, Luhtanen and Komi (1983) (6) and the higher jump of each test was recorded for further analysis. During both tests, subjects were required to place and maintain their hands on their hips during the whole jump to eliminate arm swing. In addition, players were required to maintain their legs fully extended during the flight phase. In the SJ, play ers started the jump in a maintained ( 2 seconds) squat position at 90 degrees of knee flexion without the possibility of countermovem ent previous to the jump. The $90^{\circ}$ of knee flexion and the no countermovement previous the jump was controlled using an adjustable hurdle. For the CMJ, players were allowed to perform a countermovement jump using a self-determined depth. The resting time between attempts was set at two minutes.

Sprint test. The time during a 30-m sprint in a straight line was measured by means of photocells (Witty System, Microgate, Bolzano, Italy). The players performed two maximal sprints interspersed with 3 min of passive recovery. Each s print was initiated from an individually chosen standing position $50 \mathrm{~cm}$ behind the photocell. The fastest attempt was used for analysis.

\section{Statistical Analyses}

Descriptive data (mean \pm SD) were calculated for all variables in the three sessions. A Kolmogorov-Smirnov statistical test was used to confirm data normality. To analyze the reliability of each test, the relative reliability of the different measures was analyzed using an intraclass correlation coefficient of two-way mixed single measures [ICC $(3,1)]$, calculating $90 \%$ confidence limits (CL). The ICC values were interpreted as follows: excellent (0.90 to 1.00), high $(0.70$ to 0.89$)$, moderate $(0.50$ to 0.69$)$ and low $(<0.50)$. The relative reliability values were obtained using a spreadsheet designed by Hopkins (2015). Additionally, the absolute reliability was assessed using the standard error of measurement (SEM). SEM was calculated applying the following formula (SD [pooled] $\times \sqrt{(1-I C C)}$ ) (Hopkins, 2000). SEM values were expressed in units and as a percentage of the mean score. Likewise, minimal detectable change (MDC) was calculated through the formula $(1.96 \times \mathrm{SEM} \times \sqrt{2})$. Bland-Altman plots to $90 \%$ limits of agreement were used to visualize the systematic differences between measures. A repeated-meas ures ANOVA was performed to evaluate the learning effect between different sessions being the within-subject factor. Hedges' g index (dg) was used to estimate the effect size between different sessions. The $\mathrm{dg}$ values were categorized as trivial $(\mathrm{dg}<0.2)$, small $(0.2 \leq \mathrm{dg}<$ $0.5)$, moderate $(0.5 \leq \mathrm{dg}<0.8)$ and large $(\mathrm{dg} \geq 0.8)$. The relationships between all the variables measured in the study were assessed using the Pearson's product moment correlation coefficients $(r)$ and interpreted as trivial $(<0.3)$, 
small (0.30-0.49), moderate (0.50-0.69) and large $(\geq 0.7)$. For the correlational analysis, strength parameters (estimated $1 \mathrm{RM}$ ) were normalized relative to each player' body weight. Statistical significance was set at $p<0.05$.

\section{RESULTS}

Table 1 shows the data regarding the reliability of all the variables tested in the study. The 1RM showed high to excellent relative reliability in all trials (ICC > 0.70 ) and a good absolute reliability (SEM < 10\%). Bland-Altman plots showed no systematic change among trials in $1 \mathrm{RM}$, although great reductions in the limit of agreement between trial 1-2 and trial 2-3 were found (Figure 1). Regarding the reliability in the jumping and sprinting tests, all of them showed high relative reliability (ICC $>0.8$ ) and good absolute values of reliability (SEM $<10 \%$ ).

TABLE 1

Reliability scores of the different performance test in youth soccer players.

\begin{tabular}{|c|c|c|c|c|c|c|c|c|}
\hline \multirow{3}{*}{ Test } & \multicolumn{4}{|c|}{ Reliability scores between trial1-2 } & \multicolumn{4}{|c|}{ Reliability scores between trial2-3 } \\
\hline & SEM $^{b}$ & SEM $^{a}$ & $\mathrm{MCD}^{\mathrm{a}}$ & \multirow{2}{*}{$\mathrm{ICC}_{3,1} \mathrm{~b}$} & SEM $^{\mathrm{b}}$ & SEM $^{\mathrm{a}}$ & $\mathrm{MCD}^{\mathrm{a}}$ & \multirow{2}{*}{$\operatorname{ICC}_{3,1}{ }^{b}$} \\
\hline & (\%) & Units & Units & & $(\%)$ & Units & Units & \\
\hline 1RM (kg) & $8.47(6.79-11.41)$ & 9.67 & 26.80 & $0.78(0.58-0.89)$ & $4.24(3.40-5.70)$ & 5.29 & 14.66 & $0.92(0.84-0.96)$ \\
\hline $\mathrm{SJ}(\mathrm{cm})$ & $5.18(4.16-6.98)$ & 1.82 & 5.04 & $0.85(0.70-0.93)$ & $5.32(4.27-7.17)$ & 1.83 & 5.07 & $0.82(0.66-0.91)$ \\
\hline $\mathrm{CMJ}(\mathrm{cm})$ & $6.64(5.33-8.94)$ & 2.44 & 6.76 & $0.77(0.57-0.88)$ & $4.87(3.90-6.56)$ & 1.79 & 4.96 & $0.87(0.75-0.93)$ \\
\hline T30m (s) & $1.63(1.31-2.19)$ & 0.07 & 0.19 & $0.70(0.47-0.85)$ & $1.45(1.17-1.96)$ & 0.07 & 0.19 & $0.74(0.47-0.85)$ \\
\hline
\end{tabular}

1RM: 1 repetition maximum of back squat estimated by movement velocity; SJ: Height in squat jump; CMJ: Height in countermovement jump; T30m: time in $30 \mathrm{~m}$ sprint test; SEM: standard error of measure; MDC: minimal detectable change; ICC: intraclass correlation coefficient.

${ }^{a}$ Data are presented as mean; ${ }^{b}$ Data are presented as mean and $90 \%$ CI.
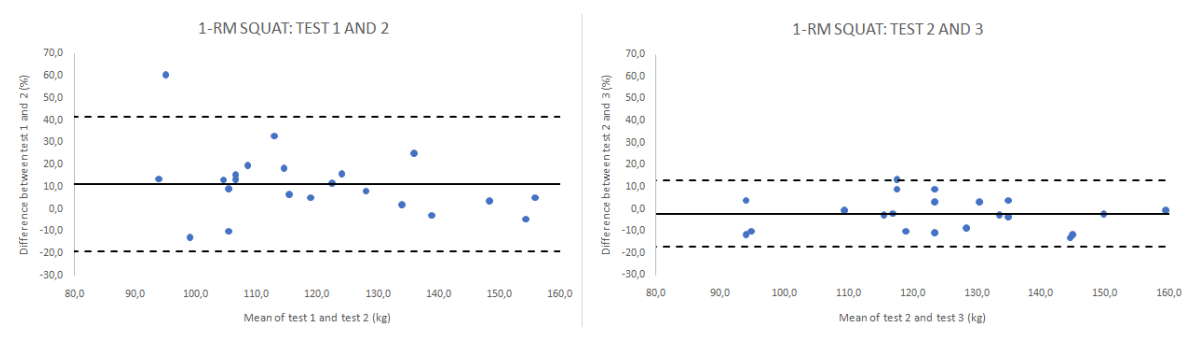

FIGURE 1: Bland-Altman plots showing the systematic differences between trials.

Concerning the strength values during the three different testing sessions, the estimated 1RM showed significant differences between trials $(\mathrm{F}=9.31 ; p<$ 0.01 ), being this estimated $1 \mathrm{RM}$ value significantly lower in the trial 1 compared with the trial 2 (dg $=0.79$; high) (Table 2$)$. 
TABLE 2

Descriptive data and comparison between trials (mean \pm SD).

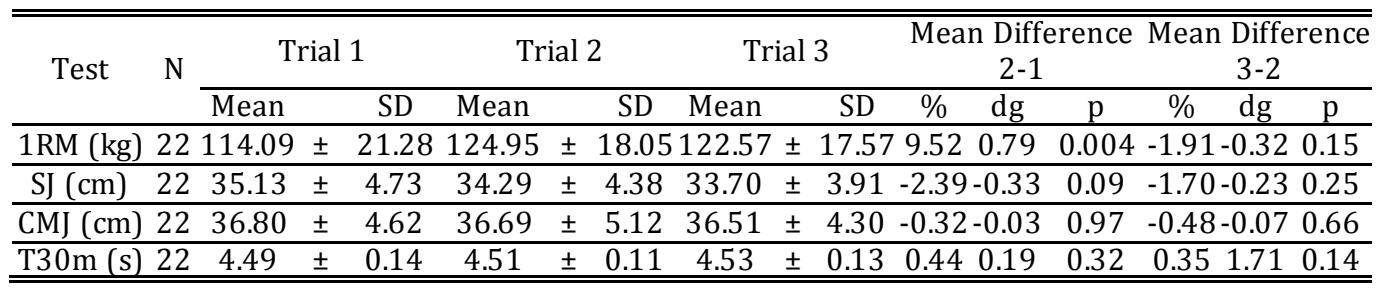

1RM: 1 repetition maximum of back squat estimated by movement velocity; SJ: Height in squat jump; CMJ: Height in countermovement jump; T30m: time in $30 \mathrm{~m}$ sprint test; $d_{g:}$ effect size; SD: standard deviation.

As is shown in Table 3, the normalized (relative to body mass) strength param eter (estimated $1 \mathrm{RM}$ ) showed significant moderate correlations with all the variables tested (SJ, CMJ, $30 \mathrm{~m}$ sprint).

TABLE 3

Relationships between strength parameters (relative to body-mass), jumping, and sprinting performance.

\begin{tabular}{cccccc}
\hline \hline Test & 1RM & PP & SJ & CMJ & T30m \\
\hline 1RM & & $.905^{* *}$ & $.538^{* *}$ & $.560^{*}$ & $-.559^{* *}$ \\
PP & & $.539^{*}$ & $.452^{*}$ & $-.412^{*}$ \\
SJ & & & $.902^{* *}$ & $-.553^{* *}$ \\
CMJ & & & & $-.634^{* *}$ \\
T30m & & & & \\
\hline \hline
\end{tabular}

1RM: 1 repetition maximum of back squat estimated by movement velocity; PP: maximum peak power of half-squat with the 60\% of 1RM; SJ: Height in squat jump; CMJ: Height in countermovement jump; T30m: time in $30 \mathrm{~m}$ sprint test ${ }^{*} p<0.05 ;{ }^{* *} p<0.01$.

\section{DISCUSSION}

The aims of this study were to assess the reliability of the 1RM estimation through movement velocity in the half-squat exercise in youth soccer players and to analyze the potential relationships between this measure and performance variables such as sprinting and jum ping ability. The main finding was that 1RM estim ation showed high values of absolute and relative reliability, although the estimated 1RM values differed significantly between testing sessions (being greater in the $2^{\text {nd }}$ testing day). With regard to correlation analysis, the estimated 1RM value showed significant correlations with both jumping and sprinting performance. 
Due to the practical impact of the strength assessment (e.g. quantifying strength levels, training intensity prescription, return-to-sport decision), it is crucial that the test used for evaluation shows high reliability. The results of the present study have shown that both relative (ICC > 0.7) and absolute (SEM < $10 \%$ ) reliability scores in the estimation of $1 \mathrm{RM}$ in the half-squat exercise ranged from high to excellent. Previous research has re ported high reliability of the direct 1RM squat evaluation in different populations such as healthy active males (ICC $=0.99$ ), and healthy active females (ICC = 0.97) (Seo et al., 2012), as well as in untrained males and females (ICC > 0.95) (Marques \& Izquierdo, 2014). In addition, Weakley et al., (2017) showed very high inter-day reliability scores for 1RM squat in youth rugby players with no experience in resistance training. Nevertheless, controversial data about the reliability of $1 \mathrm{RM}$ have been previously reported, as Ritti-Dias et al., (2011) showed significant increases in the 1RM squat when comparing the first with the third testing session. Of note that this difference was only found in the group of no previous resistance training experience. The results of the present study highlight the necessity of at least one familiarization session before obtaining a reliable measure of the 1RM through movement velocity with a submaximal load. The mechanisms underlying the inter-day increases in 1RM may be related to the inexperience in the sample analyzed. In this population, changes in movement execution (posture corrections) as well as changes in neural adaptations (e.g. motor unit recruitment, rate coding) could be responsible of such betweendays strength increments (Ritti-Dias et al., 2011).

Although the use of wearable devices and linear position transducers to control training intensity through movement velocity has increased exponentially, to date, no research has investigated the inter-day reliability of $1 \mathrm{RM}$ es timation in young soccer players. The results of the present study are in agreement with data of previous research that showed a very high intra-day reliability of movem ent velocity while performing 1RM (Balsalobre-Fernández et al., 2017; Balsalobre-Fernández, Marchante, Muñoz-López \& Jiménez, 2017). In another study, Stock, Beck, Defreitas and Dillon (2011) reported high testretest reliability values for the peak barbell velocity when using intensities ranging between 10 and $70 \%$ of $1 \mathrm{RM}$, but moder ate reliability with heavy loads ( 80 and $90 \%$ of $1 \mathrm{RM}$ ). The results of the present study do not agree with Stock et al. (2011) as the load used for 1RM prediction in the present study was superior to the $80 \%$ of $1 \mathrm{RM}$, and both the ICC and the SEM showed good values. The discrepancies between these studies may be explained by differences in the exercise used, as while Stock et al. (2011) used the bench press exercise (free weight), in the present study the exercise performed was the half-squat in a Smith machine. In fact, in a more recent study, Banyard, Nosaka, Sato and Haff (2017) reported very good absolute reliability (CV < 10\%) for velocity variables 
in the back-squat exercise using a wide range of loads (20-100\% 1RM). Nevertheless, although the 1RM estimation showed good reliability scores, the 1RM values differed significantly between trials 1-2 (see Table 2). This fact suggests a learning effect for the $1 \mathrm{RM}$ es timation test, at least, when performed by young soccer players. Therefore, for strength evaluation and subsequent training prescription, a minimum of two testing session should be performed when using the 1RM estimation through movem ent velocity using submaximal loads.

The relationships between maximal dynamic strength and both sprinting and jumping performance in soccer players have been widely reported (Comfort et al., 2014; Wisloff, Castagna, Helgerud, Jones \& Hoff, 2004). In the pres ent study, the estimated 1RM value showed significant correlations with jumping and sprinting performance. The magnitude of the relationships between 1RM and sprinting $(r=-.559)$ and jumping performance $(r=.538$ and .560 for SJ and CMJ, respectively) are in line with previous studies carried out in elite soccer players ( $r=-.710$ and .780 for sprint and CMJ) (Wisloff et al., 2004), and quite similar to those found by Comfort et al. (2014) in youth soccer players ( $r=-.672 ; .635$; and .619 for sprint, SJ, and CMJ, respectively). The results of the present study corroborate the high relationship between an estimated measure of maximal strength through movement velocity in the halfsquat, and performance in sprinting and jumping actions. Some authors have proposed that variables such as movement velocity against submaximal loads and power-related variables are better predictors of sprinting and jumping perform ance (Loturco et al., 2018), al though strong research also supported the relationships between $1 \mathrm{RM}$ values and both sprinting and jumping ability (Comfort et al., 2014; Wisloff et al., 2004). By using the 1RM estimation test through movement velocity with a submaximal load coaches would be obtaining athletes information in a comprehensive way. Therefore, this kind of testing protocols are time-efficient and provide practical data for both training prescription and to control training-induced strength changes.

\section{Conclusions}

When testing youth soccer players with no experience in resistance training, strength and conditioning coaches should be aware of the nec essity of performing at least two sessions to obtain reliable measures of 1 RM estimation though movement velocity. Once a previous familiarization session has been performed, the use of $1 \mathrm{RM}$ estimation through movement velocity in the halfsquat exercise represents a reliable and time-efficient way to assess maximal dynamic strength in youth soccer players. Consequently, these test could be used for strength evaluation as well as for the subsequent resistance training prescription. 


\section{REFERENCES}

Aguiar, M., Botelho, G., Lago, C., Maças, V., \& Sampaio, J. (2012). A review on the effects of soccer small-sided games. Journal of Human Kinetics, 33, 103-113. doi: 10.2478/v10078-012-0049-x.

Asadi, A., Ramirez-Campillo, R., Arazi, H., \& Sáez de Villarreal, E. (2018). The effects of maturation on jumping ability and sprint adaptations to plyometric training in youth soccer players. Journal of Sports Sciences, 36, 2405-2411. doi: 10.1080/02640414.2018.1459151.

Balsalobre-Fernández, C., Marchante, D., Baz-Valle, E., Alonso-Molero, I., Jiménez, S.L., \& Muñóz-López, M. (2017). Analysis of wearable and smartphone-based technologies for the measurement of barbell velocity in different resistance training exercises. Frontiers in Physiology, 28(8), 649. doi: 10.3389/fphys.2017.00649

Balsalobre-Fernández, C., Marchante, D., Muñoz-López, M., \& Jiménez, S.L. (2017). Validity and reliability of a novel iPhone app for the measurem ent of barbell velocity and 1RM on the bench-press exercise. Journal of Sports Sciences, 36(1), 64-70. doi: 10.1080/02640414.2017.1280610

Banyard, H.G., Nosaka, K., Sato, K., \& Haff, G.G. (2017). Validity of various methods for determining velocity, force, and power in the back squat. International Journal of Sports Physiology and Performance, 12(9), 1170 1176. doi: 10.1123/ijspp.2016-0627

Bosco, C., Luhtanen, P., \& Komi, P.V. (1983). A simple method for measurem ent of mechanical power in jumping. European Journal of Applied Physiology and Occupational Physiology, 50(2), 273-82.

Carling, C., Le Gall, F., \& Dupont, G. (2012). Analysis of repeated high-intensity running performance in professional soccer. Journal of Sports Sciences, 30, 325-336. doi: 10.1080/02640414.2011.652655

Comfort, P., Stewart, A., Bloom, L., \& Clarkson, B. (2014). Relations hips between strength, sprint, and jump performance in well-trai ned youth soccer players. Journal of Strength and Conditioning Research, 28(1), 173-177. doi: 10.1519/JSC.0b013e318291b8c7

Conceição, F., Fernandes, J., Lewis, M., Gonzaléz-Badillo, J.J., \& Jimenéz-Reyes, P. (2016). Movem ent velocity as a measure of exercise intensity in three lower limb exercises. Journal of Sports Sciences, 34, 1099-1106. doi: 10.1080/02640414.2015.1090010

Faude, O., Koch, T., \& Meyer, T. (2012). Straight sprinting is the most frequent action in goal situations in professional football. Journal of Sports Sciences, 30, 625-631. doi: 10.1080/02640414.2012.665940

González-Badillo, J.J., \& Marques, M.C. (2010). Relationship between ki nematic factors and countermovement jump height in trained track and field 
athl etes. Journal of Streng th and Conditioning Research, 24, 3443-3447. doi: 10.1519/JSC.0b013e3181bac37d.

González-Badillo, J.J., \& Sánchez-Medina, L. (2010). Movement velocity as a measure of loading intensity in resistance training. International Journal of Sports Medicine, 31(5), 347-352. doi: 10.1055/s-0030-1248333.

Hopkins, W. (2000). Measures of reliability in sports medicine and science. Sports Medicine, 30(1), 1-15.

Hopkins, W. (2015). Spreadsheets for analysis of validity and reliability. Sportscience, 21.

Jidovtseff, B., Harris, N.K., Cri elaard, J.M., \& Cronin, J.B. (2011). Using the load velocity relationship for $1 \mathrm{RM}$ prediction. Journal of Strength and Conditioning Research, 25, 267-270. doi: 10.1519/JSC.0b013e3181b62c5f.

Kraemer, W.J., Adams, K., Cafarelli, E., Dudley, G.A., Dooly, C., Feigenbaum, M.S., Fleck, S.J. et al. (2002). Progression models in resistance training for healthy adults. Medicine \& Science in Sports \& Exercise, 34, 364-380. doi: 10.1249/MSS.0b013e3181915670.

Levinger, I., Goodman, C., Hare, D.L., Jerums, G., Toia, D., \& Selig, S. (2009). The reliability of the 1RM strength test for untrained middle-aged individuals. Journal of Science and Medicine in Sport, 12, 310-316, 2009.

Loturco, I., Kobal, R., Moraes, J.E., Kitamura, K., Cal-Abad, C.C., Pereira, L.A., \& Nakamura, F,Y. (2017). Predicting the maximum dynamic strength in bench press: the high precision of the bar velocity approach. Journal of Strength and Conditioning Research, 31(4), 1127-1131, 2017. doi: 10.1519/JSC.0000000000001670.

Loturco, I., Pereira, L.A., Abad, C.C., Gil, S., Kitamura, K., Kobal, R., \& Nakamura, F.Y. (2016). Using bar velocity to predict maximum dynamic strength in the half-squat exercise. International Journal of Sports Physiology and Performance, 11, 697-700. doi: 10.1123/ijspp.2015-0316

Loturco, I., Suchomel, T., James, L.P., Bishop, C., Abad, C.C., Pereira, L.A., \& McGuigan, M.R. (2018). Selective influences of maximum dynamic strength and bar-power output on team sports performance: a comprehensive study of four different disciplines. Frontiers in Physiology, 17(9), 1820. doi: 10.3389/fphys.2018.01820

Marques, M.C., \& Izquierdo, M. (2014). Kinetic and kinematic associations between vertical jump performance and $10-\mathrm{m}$ sprint time. Journal of Strength and Conditioning Research, 28(8), 2366-2371. doi: 10.1519/JSC.0000000000000390

McCurdy, K., Langford, G.A., Cline, A.L., Doscher, M., \& Hoff, R. (2004). The reliability of 1- and $3 \mathrm{RM}$ tes ts of unilateral strength in trained and untrained men and women. Journal of Sport Science and Medicine, 3, 190-196. 
Ritti-Dias, R.M, Avelar, A., Salvador, E.P., \& Cyrino, E.S. (2011). Influence of previous experience on resistance training on reliability of one-repetition maximum tests. Journal of Strength and Conditioning Research, 25(5), 14181422. doi: 10.1519/JSC.0b013e3181d67c4b.

Rodríguez-Rosell, D., Franco-Márquez, F., Pareja-Blanco, F., Mora-Custodio, R., Yáñez-García, J.M., González-Suárez, J.M., \& González-Badillo, J.J. (2016). Effects of 6 weeks resistance training combined with plyometric and speed exercises on physical performance of pre-peak-height-velocity soccer players. Interna tional Journal of Sports Physiology and Performance, 11, 240246. doi: 10.1123/ijspp.2015-0176.

Rontu, J.P., Hannula, M.I., Leskinen, S., Linnamo, V., \& Salmi, J.A. (2010). Onerepetition maximum bench press performance estimated with a new accelerometer method. Journal of Strength and Conditioning Research, 24, 2018-2025. doi: 10.1519/JSC.0b013e3181c7c433.

Ryman-Augustsson, S., \& Svantesson, U. (2013). Reliability of the 1 RM bench press and squat in young women. European Journal of Physiotherapy, 15, 118-126. doi: 10.3109/21679169.2013.810305

Seo, D.I., Kim, E., Fahs, C.A., Rossow, L., Young, K., Ferguson, S.L., ... et al. (2012). Reliability of the one-repetition maximum test based on muscle group and gender. Journal of Sport Science and Medicine, 11: 221-225.

Stock, M.S., Beck, T.W., Defreitas, J.M., \& Dillon, M.A. (2011). Test-retest reliability of barbell velocity during the free-weight bench-press exercise. Journal of Strength and Conditioning Research, 25(1), 171-177. doi: 10.1519/JSC.0b013e318201bdf9.

Stølen, T., Chamari, K., Castagna, C., \& Wisløff, U. (2005). Physiology of soccer: an update. Sports Medicine, 35, 501-536.

Stone, N.M., \& Kilding, A.E. (2009). Aerobic conditioning for team s port athletes. Sports Medicine, 39(8), 615-642. doi: 10.2165/00007256-20093908000002.

Tagesson, S.K.B., \& Kvist, J. (2007). Intra- and interrater reliability of the establishment of one repetition maximum on squat and seated knee extension. Journal of Strength and Conditioning Research, 21(3), 801-807.

Weakley, J., Till, K., Darrall-Jones, J., Roe, G.A.B., Phibbs, P.J., Read, D.B., \& Jones, B.L. (2017). The influence of resistance training experience on the betweenday reliability of commonly used strength measures in male youth athletes. Journal of Strength and Conditioning Research, 31(7), 2005-2010. doi: 10.1519/JSC.0000000000001883.

Wisløff, U., Castagna, C., Helgerud, J., Jones, R., \& Hoff, J. (2004). Strong correlation of maximal squat strength with sprint performance and vertical jump height in elite soccer pl ayers. British Journal of Sports Medicine, 38(3), 285-288. doi:10.1136/bjsm.2002.002071. 